\title{
Alternativas inteligentes para a preservação do patrimônio cultural no contexto das smart cities
}

\author{
Larissa Fernandes Dutra \\ Universidade Federal de Minas Gerais, Escola de Ciência da Informação, Belo Horizonte, MG, Brasil \\ larissadutraa@gmail.com \\ Renata Maria Abrantes Baracho Porto \\ Universidade Federal de Minas Gerais, Escola de Ciência da Informação, Belo Horizonte, MG, Brasil \\ renatabaracho@ufmg.br
}

DOI: https://doi.org/10.26512/rici.v13.n1.2020.26210

Recebido/Recibido/Received: 2019-07-16

Aceitado/Aceptado/Accepted: 2019-11-08

ARTIGOS DE REVISÃo

Resumo: O objetivo deste artigo é identificar alternativas inteligentes para a preservação do patrimônio cultural em um contexto de smart cities. Para isso, realizou-se uma revisão de literatura contemplando artigos de 2004 a 2019 recuperados das plataformas Google Acadêmico e Portal Capes. As palavraschaves utilizadas para busca foram: smart cities e preservação patrimonial; cidades inteligentes e preservação patrimonial; patrimônio inteligente e smart heritage. Dos 80 artigos recuperados, foram selecionados aqueles que propusessem alternativas inteligentes para a conservação do patrimônio cultural. A partir de então, foi possível identificar um conjunto de ferramentas voltadas para a preservação do patrimônio que pudessem ser refletidas no âmbito das cidades inteligentes. Por meio do conteúdo selecionado, identifica-se que as técnicas de digitalização 3D, o Building Information Modeling (BIM), os aplicativos móveis para gestão integrada da preservação patrimonial e os sensores para coleta e análise de dados dos acervos em tempo real,são algumas das possibilidades para o planejamento da preservação do patrimônio cultural no contexto das smart cities.

Palavras-chave: conservação patrimonial. cidade inteligente. tecnologias da informação e da comunicação.

\section{Alternativas inteligentes para la preservación del patrimonio cultural en el contexto de las ciudades inteligentes.}

Resumen: El objetivo de este artículo es identificar alternativas inteligentes para la preservación del patrimonio cultural en un contexto de smart cities. Para ello, se llevó a cabo una revisión de la literatura contemplando artículos de 2004 a 2019 recuperados de las plataformas Google Académico y Portal Capes. Las palabras clave utilizadas para la búsqueda fueron: smart cities e preservación patrimonial; ciudades inteligentes e preservación patrimonial; patrimonio inteligente e smart heritage. De los 80 artículos recuperados, se seleccionaron aquellos que propusieron alternativas inteligentes para la conservación del patrimonio cultural. A partir de entonces, fue posible identificar un conjunto de herramientas destinadas a preservar el patrimonio que podría reflejarse en el alcance de las smart cities. A través del contenido seleccionado, se identifica que las técnicas de escaneo 3D, el Building Information Modeling (BIM), las aplicaciones móviles para la gestión integrada de la preservación de activos y los sensores para la recopilación y análisis de datos de colecciones en el tiempo reales son algunas de las posibilidades para planificar la preservación del patrimonio cultural en el contexto de las smart cities.

Palabras clave: conservación de activos. ciudad inteligente. tecnologías de la información y la comunicación. 
Abstract: The aim of this article is to identify intelligent alternatives for the preservation of cultural heritage in a context of smart cities. For this, a literature review was conducted contemplating articles from 2004 to 2019 retrieved from the Google Scholar and Portal Capes platforms. The keywords used for search were smart cities e preservação patrimonial; cidades inteligentes e preservação patrimonial; patrimônio inteligente and smart heritage. Of the 80 articles recovered, those who proposed intelligent alternatives for the conservation of cultural heritage were selected. From then on, it was possible to identify a set of tools aimed at preserving the heritage that could be reflected in the scope of the smart cities. Through the selected content, it is identified that the 3D scanning techniques, the Building Information Modeling (BIM), the mobile applications for integrated management of asset preservation and the sensors for acquisition and analysis of data from the collections in real time are, some of the possibilities for planning the preservation of cultural heritage in the context of the smart cities.

Keywords: asset conservation. smart city. information and communication technologies.

\section{Introdução}

O mundo testemunhou, nas últimas décadas, uma constante tendência ascendente na urbanização. A maior parte da população global (54\%) está atualmente concentrada em áreas urbanas e, segundo as Organizações das Nações Unidas (ONU, 2015), até o ano de 2050 chegaremos a marca de $70 \%$ de indivíduos vivendo em cidades.Essa tendência coloca uma pressão excessiva sobre o patrimônio cultural urbano, que sobrevive, por muitas vezes, em meio a ataques terroristas, alterações climáticas, pressão imobiliária e má gestão dos recursos econômicos governamentais, resultando, em alguns casos, em danos irreversíveis e perda definitiva. Sabe-se, todavia,que o legado patrimonial é tanto essencial para o crescimento econômico das cidades - que vivem de atividade turística, por exemplo - quanto para a preservação da memória social e identidade cultural dos povos. Assim, a sua proteção é um dever coletivo e moral (RIGANTI, 2017).

O Brasil, como um dos países mais populosos do mundo, sofre também com os efeitos de uma rápida urbanização em um contexto de alta desigualdade social e ineficiência da gestão dos recursos públicos para manutenção e salvaguarda do seu patrimônio. Um exemplo disto pode ser verificado a partir do incêndio ocorrido em setembro de 2018 no Museu Histórico Nacional do Rio de Janeiro (MHN-RJ). De acordo com Kátia Bogéa (2018) -presidente do Instituto do Patrimônio Histórico Artístico e Cultural (IPHAN) - mesmo após diversas denúncias quanto aos problemas estruturais das instalações do museu e irregularidades elétricas, não se tomou, por parte da administração pública, nenhuma ação que fosse capaz de livrá-lo do referido episódio. Consequência, foi que, das mais de 20 milhões de peças que compunham o acervo, cerca de $75 \%$ foram afetadas pelas chamas, levando consigo parte da memória da população brasileira (KELLNER, 2019).

Estudos recentes, que se dedicaram a pesquisara relação atual do patrimônio cultural com o ambiente urbano, como por exemplo, os de Kehl, Siviero e Isatto (2011), Riganti (2017) e 
Segurado (2017)propõem, que uma ${ }^{1}$ das alternativas para se mitigar catástrofes, tal qual a do MHN, se revela por meio da utilização das tecnologias da informação e da comunicação (TIC) na aplicação de melhorias que ambicionem a preservação e proteção desses espaços.

Para Figueiredo (2018)o interesse em se aplicar novas tecnologias aos mais diversos setores urbanos - como mobilidade, segurança, saúde e cultura - emerge, principalmente,a partir do início do século XXI, quando, começa-se a discutir a aplicação de sistemas, sensores, bancos de dados interoperáveis e aparelhagem de ponta nas cidades, tornando-as, cada vez mais, "inteligentes". Objetivo disso seria o aumento da qualidade de vida da população, a preservação de edifícios históricos, o desenvolvimento da malha urbana, o crescimento econômico, etc. Assim, essas cidades inteligentes, no inglês, "smart cities", nasceram com a premissa de tornar os centros urbanos, cada vez mais, eficientes e habitáveis por meio da inserção das tecnologias no seu planejamento, gerenciamento e monitoramento(BARACHO et al., 2019).

Nesse sentido, o artigo objetiva, por meio de uma revisão de literatura, localizar, analisar, sintetizar e interpretar alternativas que utilizem as TIC para a preservação do patrimônio cultural urbano e que possam, ainda, ser refletidas no contexto das cidades inteligentes .Para isso, foram recuperadas 80 produções, incluindo teses, dissertações, artigos científicos e publicações diversas -brasileiras e internacionais - com filtro cronológico dos anos 2004 a 2019. As bases de dados utilizadas foram o Google Acadêmico e o Portal de Periódicos da Capes, considerando para busca as palavras-chaves: "smart cities e preservação patrimonial"; "cidades inteligentes e preservação patrimonial"; "patrimônio inteligente" e "smart heritage". Ao final da investigação, por meio de parâmetros de exclusão e análise de conteúdo, selecionou-se as produções mais significativas -correlacionadas com os objetivos delineados neste artigo- e, então, foi possível detectar e listar algumas das alternativas inteligentes que vêm sendo trabalhadas para preservação do patrimônio cultural urbano.

\section{O discurso e a prática do fenômeno Smart City}

Historicamente, a ideia de smart city surge na primeira década do século XXI quando, segundo Figueiredo (2018), empresas de tecnologia e incorporadoras imobiliárias se aliaram para construir provas de conceito do que poderia vir a ser a cidade do futuro, que seria inteligente a ponto de evitar sozinha calamidades como a do incêndio do Museu Histórico Nacional (MHN, RJ), conforme citado acima, além de propor uma ideia de poluição zero, plena conectividade, trânsito sem dificuldades e edifícios 100\% inteligentes. Renomados escritórios 
de arquitetura, nesse sentido, foram contratados para projetar cidades inteiramente novas, a serem erguidas do pó com a mais avançada tecnologia para mostrar que a cidade sustentável não apenas estaria sob o nosso alcance como também teria um excelente padrão de vida.

A cidade de Masdar - nos arredores de Abu Dhabi, na Arábia Saudita - foi uma das smart cities pioneiras. Projetada pelo escritório de arquitetura Foster \& Partners em 2007 a cidade teria um design totalmente irreverente, sem nenhum carro nas ruas, pois, a malha de transportes seria totalmente subterrânea. Contudo, após várias atualizações por parte dos projetores sobre a data de finalização da construção da cidade, descartou-se a proposta de "cidade sem automóvel" mediante as dificuldades de execução do plano e os avanços dos carros elétricos comerciais.

Além disso, não houve adesão por parte da população no sentido de se mudar para a localidade, já que, atualmente, Masdar conta com menos da metade da ocupação planejada incialmente (FIGUEIREDO, 2018). Para Rozestraten (2016) por terem sido construídas por meio de um imaginário empresarial, essas cidades, a exemplo de Masdar, se mostraram carentes de elementos fundamentais que constituem o urbano, como o pulsar da diversidade cultural, dos espaços públicos, e de elementos urbanísticos e sociais essenciais, se aproximando muito do termo smart, pela engenharia de sistemas, e pouco do termo city.

A partir de 2007 os paradigmas de arquitetura de redes e sistemas começaram a mudar em decorrência do desenvolvimento de algumas tecnologias-chave. É o caso das novas gerações de rede de telefonia móvel, que permitiram por meio dos sistemas $2 \mathrm{G}, 3 \mathrm{G}$ e $4 \mathrm{G}$ o aumento significativo na velocidade da transmissão de dados e a estabilidade da conexão, levando a usos cada vez mais elaborados da internet. Em 2007 a Apple também lançaria o seu primeiro Iphone que modificou para sempre não somente o mercado de telefonia móvel, mas também a nossa interação diária com a tecnologia.

Na primeira década do século XXI surgiram ainda componentes de comunicação via rádio, sensores e processadores cada vez mais poderosos pequenos e econômicos - tanto de custo quanto de consumo energético - o suficiente para que coubessem todos juntos em dispositivos portáteis com poder computacional para executar grande variedade de tarefas complexas. A ideia de ligar objetos na internet começa a ganhar força neste contexto, fortemente impulsionado por fabricantes de chips, companhia de telecomunicação e empresas de tecnologia, que viriam a prover os insumos para a concretização do conceito de Internet das Coisas (Internet of things /loT). A loT, desse modo, é um projeto baseado na ligação da Internet a tudo que for possível: carros, coleiras de cachorros, geladeiras, cafeteiras, sinais de trânsito, dentre muitos outros com o objetivo de coletar dados que possam ser utilizados para a tomada de decisão, muitas vezes, em tempo real(BARACHO et al., 2019). 
Esses desenvolvimentos tecnológicos e as subsequentes mudanças de como interagimos com o meio ambiente levou a uma nova projeção de redes e sistemas que poderiam compor inéditos projetos de smart cities. Entendendo que a criação de cidades a partir do zero não seria a opção mais adequada - devido à falta de características propriamente urbanas observada nessas localidades, conforme vimos anteriormente - a tendência posterior se pautou para a smartificação de cidades já existentes com incentivos do próprio Estado para tal.

Nesse período constata-se uma grande incerteza do próprio conceito de smart cities e quais seriam os parâmetros para transformar em smart, uma cidade comum. Segundo Figueiredo (2018) o projeto de Barcelona, por exemplo, envolveu a implementação de infraestrutura de telecomunicação, sensoriamento remoto, eletrônica embarcada e processamento massivo de dados na tentativa de permitir à cidade perceber, interpretar e reagir de maneira dinâmica a situações complexas, buscando aumentar a visibilidade operacional e a capacidade de ação dos gestores públicos por meio da coleta e processamento de informação sobre diferentes aspectos urbanos. Assim, iniciativas de smartificação começam a ser tomadas ao redor do mundo, porém, de maneiras distintas, concretizando a indefinição do discurso e prática das cidades inteligentes, o que também levou aos acadêmicos em universidades a começarem a problematizar sua definição.

$\mathrm{Na}$ mídia, de uma forma geral, são mostrados casos de sucesso de smartificação predominando um reforço do sentimento de competitividade entre as cidades. A busca por investimentos faz com que essa pauta entre na agenda dos governos locais e gere uma corrida por projetos de transformação do transporte público, edifícios, saúde, educação, turismo, e outros componentes urbanos em smart. Resultado disso, é a elaboração dos rankings especializados que se propõem a definir quais são as cidades mais inteligentes do mundo, cada ranking com seu universo amostral, metodologia e critérios (RIGANTI, 2017).

Atualmente o fenômeno das smart cities perpassa por mais uma tendência, denominada por Figueiredo (2018), "minas de dados". Para o autor, com o progresso das loT e das redes $3 \mathrm{G}$ e 4G a internet salta de 500 milhões de dispositivos conectados em 2003, para 12,5 bilhões em 2010 com previsão de chegada aos 50 bilhões em 2020. Cada um desses dispositivos produz dados: uma cafeteira smart, por exemplo, é capaz de memorizar e automatizar a exata dosagem de café que o usuário prefere conforme o horário do dia. Pode ainda ter um microfone para captar comandos de voz ou sensores que identifiquem por meio de conectores ao celular qual deverá ser o sabor da capsula a ser utilizada. Todas essas informações, produzidas continuamente, são armazenadas pelas empresas e permitem uma série de análises que até a década passada seriam inviáveis. 
Percebe-se, desse modo, que a tendência atual é de geração de dados na maior quantidade possível - fenômeno denominado big data - para que deles se possa extrair valor a partir de relações pensadas a posteriori. O resultado é um conjunto de dados tão vasto, diverso e veloz que ultrapassa a capacidade das tradicionais ferramentas e técnicas de coleta, armazenamento, análise e visualização de informações, daí o entendimento das cidades como verdadeiras "minas de dados".

As prefeituras municipais já manejam esforços para oferta de dados abertos (open data) ao cidadão que são ricas fontes de informação para elaboração de projetos, tomadas de decisões em âmbito legislativo, etc. O Portal de Dados Abertos da Prefeitura Municipal de Belo Horizonte, por exemplo, possui 73 conjuntos de dados como o georreferenciamento de bairros, índices de qualidade de vida urbana e relação de ocorrências de acidentes de trânsito,objetivando, segundo o portal, a interlocução entre atores da sociedade e o governo para pensar a melhor utilização dos dados,com a finalidade de se construir uma cidade melhor para se viver, trabalhar e visitar (BELO HORIZONTE, 2019).

Assim, cientes das novas possibilidades surgindo a partir do big data, as empresas de tecnologia da informação viram na loT o como fazer e na smart city a oportunidade de distribuir a tecnologia pelo território urbano: hoje em dia, "se os dados são o novo ouro - ou petróleo - as cidades são as novas minas" (FIGUEIREDO, 2018 p. 52).

Nesse sentido, entende-se que as pesquisas em smart cities revelam uma tendência mundial: o esforço em aliar as necessidades do urbano às novas tecnologias da informação e da comunicação com o objetivo de, além de muitos outros, melhorar a qualidade de vida da população. Com isso, podemos inferir que a preservação dos bens culturais que são compostos tanto dos edifícios de tijolo e argamassa, quanto do conhecimento social intangível proveniente dos acervos das bibliotecas, arquivos, museus e outros, podem, também, se beneficiar de alternativas inteligentes para a sua preservação. É sobre isso que discutiremos a seguir.

\section{O desafio da preservação do patrimônio cultural em ambientes urbanos}

Segundo uma acepção clássica, o conceito de patrimônio refere-se ao legado que herdamos do passado e que transmitimos a gerações futuras. Para o Dicionário Aurélio de Língua Portuguesa (2019), por exemplo, patrimônio significa uma "herança comum ou coletiva" de caráter material ou imaterial. As línguas românicas usam o termo patrimonium derivado do latim para se referirem à "propriedade herdada do pai ou dos antepassados, uma herança". Os alemães usam apalavra denkmalpflege para expressar o nosso equivalente à palavra patrimônio, ligando seu significado "ao cuidado dos monumentos, daquilo que nos faz 
pensar". Já o inglês adotou heritage para expressar "àquilo que foi ou pode ser herdado", mas que, pelo mesmo processo de generalização que afetou as línguas românicas e seu uso dos derivados de patrimonium, também passou a ser usado como uma referência aos monumentos herdados das gerações anteriores (FUNARI, 2001).

Aquilo que é ou não é patrimônio, segundo Silva (2000), depende do que, para um determinado coletivo humano e num determinado lapso de tempo, se considera socialmente digno de ser legado a gerações futuras. Trata-se de um processo simbólico de legitimação de poder social e cultural de determinados objetos, símbolos ou significados que conferem a um grupo um sentimento coletivo de identidade. Assim sendo, o patrimônio cultural compreenderá todos aqueles elementos presentes na memória social que fundamentam a identidade de um grupo e que os diferenciam dos demais.

O professor Jan Assmann, da Universidade de Konstanz na Alemanha, em entrevista para o Instituto de Estudos Avançados da Universidade de São Paulo (UNIVERSIDADE DE SÃO PAULO, IEA, 2013) menciona que a memória social, por esse ângulo, é constituída por heranças simbólicas materializadas em textos, ritos, monumentos, documentos, objetos, escrituras sagradas e patrimônios diversos que funcionam como gatilhos para acionar significados associados ao que passou. Para o pesquisador, nesse sentido, o patrimônio cultural e a memória social detêm forte ligação com a criação e desenvolvimento do conhecimento social humano, passado de geração em geração.

A explicação para este fenômeno é clara: o patrimônio detém, enraizado em si, uma junção de memórias destrinchadas em acervos, como peças museológicas, documentos reais, livros raros, e objetos dos mais diversos que carregam o conhecimento e a identidade social de um povo, por meio de informações registradas e também por objetos históricos, que contam narrativas sem sequer, escrever uma única palavra. Para Innarelli (2011) a nossa sociedade preserva a sua cultura através da transmissão do conhecimento e de sua consequente apropriação. Esse conhecimento, quando registrado e transmitido, poderá gerar outros estados e formatos de conhecimento, garantindo um ciclo de evolução sociocultural e, consequentemente, assegurando a evolução do próprio ser humano.

Entende-se, nesse âmbito, que o patrimônio cultural ocupa um papel significativo no desenvolvimento e aprendizado social, fazendo com que as novas gerações se informem e se apropriem do legado deixado pelos seus antepassados. A preservação desse patrimônio nas cidades contemporâneas, assim, é uma pauta de importância indiscutível.

Riganti (2017) relata, no entanto, que apesar da sua relevância, o patrimônio cultural nas cidades enfrenta uma pressão excessiva que o torna cada vez mais frágil. A poluição, a chuva ácida, a falta de políticas governamentais voltadas para a sua valorização, e as calamidades 
urbanas são alguns dos fatores citados pela pesquisadora. Moura et al. (2012) apontam que uma série de artefatos históricos e documentos de grande valor têm sido perdidos ao longo do tempo devido à deficiência dos mecanismos de preservação, o que ocasiona prejuízos imensuráveis provocados por fatores como intempéries ou manuseio inadequados.

A Catedral de Notre-Dame em Paris, por exemplo, data de 1163 e recebe, segundo Vannucci et al. (2019) cerca de 13 milhões de visitantes ao ano. Mesmo sendo um dos monumentos históricos mais frequentados da Europa, acabou tornando-se cenário de um incêndio causado por falha na execução do processo de restauro do seu telhado, no dia 15 de abril de 2019. O incêndio destruiu grande parte da estrutura original do telhado, composta por madeira de aproximadamente 1300 carvalhos e coberta com 210 toneladas de telhas de chumbo, além de danificar parte da abóbada da catedral, do corredor principal, do centro de orações e do seu acervo (VANNUCCI et al. 2019). Para os autores, a restauração do monumento durará, provavelmente, décadas.

O Museu Histórico Nacional do Rio de Janeiro, que se configura, segundo o seu site oficial, como a instituição científica mais antiga do Brasil -com mais de 200 anos de história - reunia materiais de botânica, zoologia e animais empalhados, além de coleções de moedas, artefatos históricos e obras de arte das mais variadas, detendo o quinto maior acervo museal do mundo (MUSEU..., RJ, 2019). No dia 02 de setembro de 2018, em contrapartida, a instituição se viu palco de um incêndio oriundo de falhas na estrutura elétrica do monumento, perdendo cerca de 75\% da sua coleção (MUSEU..., RJ, 2019). O seu acervo reunia:Luzia, o mais antigo fóssil humano da América datado de mais de 11 mil anos; o dinossauro Maxakalisaurustopai, proveniente de Minas Gerais, que foi o primeiro dinossauro de grande porte montado para exposição em nosso país; um acervo de mais de cinco milhões de exemplares de insetos que detinha a maior diversidade entomológica (diversidade de insetos) de toda a América do Sul e muitos outros(MUSEU..., RJ, 2019).

Grandes calamidades, como a do Museu Histórico Nacional, no Rio de Janeiro e o da Catedral de Notre-Dame, em Paris, afetam, além do patrimônio cultural edificado, também os registros de descobertas importantes para a ciência, podendo, inclusive, comprometer pesquisas científicas, já que levam consigo, parte do conhecimento social de suas nações.É nesse sentido que discorre a reflexão quanto as alternativas inteligentes, por intermédio das tecnologias da informação e da comunicação para preservação, do patrimônio cultural, principalmente, no contexto atual das cidades inteligentes, que tendem a utilizar as TIC para melhoria da gestão dos setores urbanos.

\section{Metodologia}


Para Bento (2012) a revisão da literatura é um método que envolve localizar, analisar, sintetizar e interpretar a investigação prévia relacionando com a temática de interesse. Assim, essa pode ser compreendida como indispensável não somente para definir bem o problema, mas também para obter uma ideia precisa quanto ao estado atual dos conhecimentos sobre um determinado assunto e as suas lacunas.

Nesse sentido, no intuito de atingir os objetivos propostos neste artigo, realizou-se uma revisão de literatura relacionada a temática da preservação, as tecnologias da informação e da comunicação e as cidades inteligentes. Para isso, foram definidos seis passos metodológicos, conforme Figura 1.

Figura 1: Passo a passo

metodológico

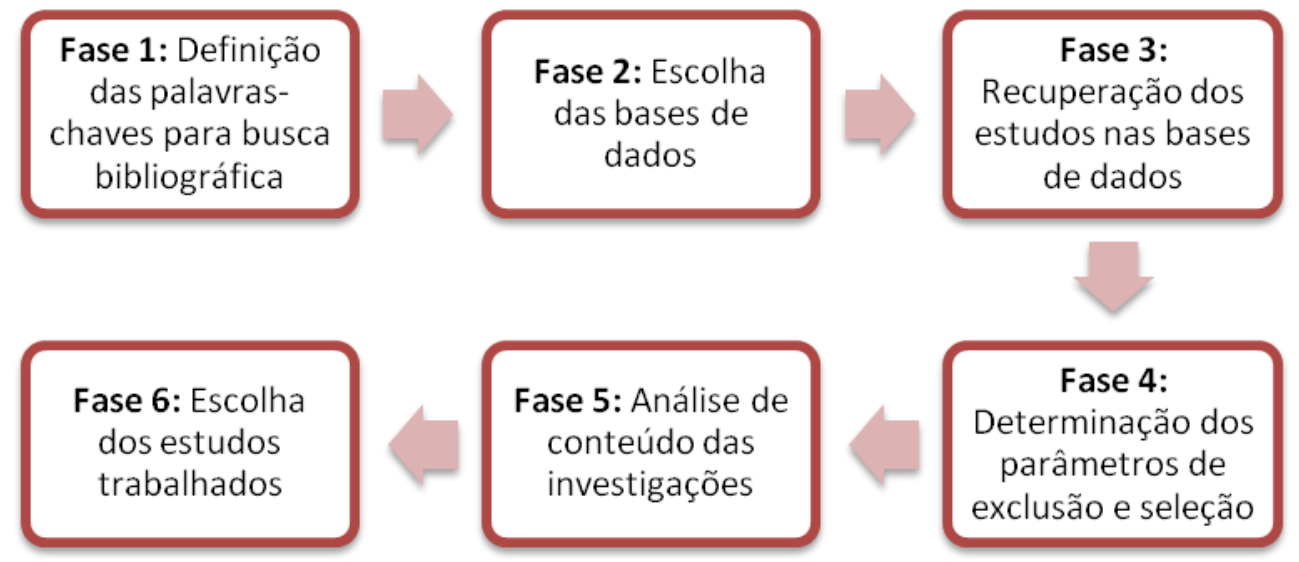

Fonte: Elaboração própria (2019)

Inicialmente, foram definidas as palavras-chaves para busca de estudos que compactuassem com os objetivos da presente investigação. As palavras-chave utilizadas foram: "smart cities e preservação patrimonial"; "cidades inteligentes e preservação patrimonial"; "patrimônio inteligente" e "smart heritage". Na sequência, foram definidas as bases de dados utilizadas para a recuperação de investigações. O Google Acadêmico e o Portal de Periódicos da Capes foram os escolhidos, com o uso de filtro somente cronológico, apanhando trabalhos entre os anos de 2004 e 2019.

No terceiro momento metodológico, foram recuperadas 80 investigações, sendo 40 resgatadas do Portal Capes e 40 do Google Acadêmico. Quanto aos tipos dessas investigações, foram localizadas teses, dissertações, artigos científicos e publicações diversas - brasileiras e internacionais. Considera-se que o número total de estudos escolhidos para análise foi adequado, pois, durante o processo de construção do presente artigo,percebeu-se que a quantidade de pesquisas registradas que relacionem a temática do patrimônio urbano com as 
novas tecnologias da informação e da comunicação não é grandemente significativa. Ao longo do tempo de construção desta investigação, inclusive, percebeu-se que ainda são poucos os estudos que refletem a preservação do patrimônio cultural no escopo das cidades inteligentes.

Assim, como parâmetro de exclusão e seleção do conteúdo recuperado, foram analisados, de cada um dos 80 estudos, ao longo de seis meses, as palavras-chave, título, resumo e resultados. Selecionou-se, nesse sentido, apenas aqueles trabalhos que propusessem ao menos uma alternativa inteligente para a preservação do patrimônio cultural e que essa alternativa pudesse ser aplicada no contexto das smart cities. Desse modo, a Tabela 1 sintetiza as investigações selecionadas e suas respectivas contribuições em se tratando de alternativas que utilizem as TIC para a preservação do patrimônio cultural. Aprofundaremos sobre o conteúdo descrito abaixo na próxima seção.

Tabela 1: Investigações selecionadas por meio da Revisão de Literatura

\begin{tabular}{|c|c|c|c|}
\hline Título da investigação & Autor (es) & Ano & $\begin{array}{c}\text { Alternativa inteligente } \\
\text { proposta }\end{array}$ \\
\hline $\begin{array}{c}1 \text { - Monitoramento e } \\
\text { controle térmico para } \\
\text { preservação de acervos }\end{array}$ & Guths & 2004 & $\begin{array}{l}\text { Utilização de sensores } \\
\text { conectados ao acervo } \\
\text { para coleta e análise de } \\
\text { dados em tempo real }\end{array}$ \\
\hline $\begin{array}{l}2 \text { - Design an Immersive } \\
\text { Interactive Museum in } \\
\text { Second Life }\end{array}$ & Zhu, Xiang e Shenghong & 2007 & $\begin{array}{c}\text { Técnicas de } \\
\text { digitalização em 3D }\end{array}$ \\
\hline $\begin{array}{c}3 \text { - A tecnologia BIM na } \\
\text { documentação e gestão } \\
\text { da manutenção de } \\
\text { edifícios históricos }\end{array}$ & Kehl, Siviero e Isatto & 2011 & $\begin{array}{l}\text { Building Information } \\
\text { Modeling (BIM) }\end{array}$ \\
\hline $\begin{array}{c}4 \text { - MUSERT: Um museu } \\
\text { virtual em } 3 D \text { para a } \\
\text { preservação do } \\
\text { Patrimônio Histórico e } \\
\text { Cultural }\end{array}$ & Moura et al & 2012 & $\begin{array}{c}\text { Técnicas de } \\
\text { digitalização em 3D }\end{array}$ \\
\hline $\begin{array}{c}5 \text { - As interfaces de } \\
\text { realidade virtual no } \\
\text { século XXI }\end{array}$ & Gobira e Mozelli & 2016 & $\begin{array}{c}\text { Técnicas de } \\
\text { digitalização em 3D }\end{array}$ \\
\hline $\begin{array}{c}6 \text { - A gestão da } \\
\text { informação na proteção } \\
\text { do patrimônio cultural } \\
\text { material }\end{array}$ & Araujo & 2017 & $\begin{array}{l}\text { Aplicativos móveis para } \\
\text { gestão participativa da } \\
\text { preservação patrimonial }\end{array}$ \\
\hline $\begin{array}{c}7 \text { - Sistema de Cloud } \\
\text { baseado em dispositivo } \\
\text { multi-sensor para } \\
\text { aplicação em edifícios } \\
\text { históricos }\end{array}$ & Segurado & 2017 & $\begin{array}{l}\text { Utilização de sensores } \\
\text { conectados ao acervo } \\
\text { para coleta e análise de } \\
\text { dados em tempo real }\end{array}$ \\
\hline $\begin{array}{c}8 \text { - Mapa de danos de } \\
\text { edificações históricas } \\
\text { utilizando a } \\
\text { metodologia BIM }\end{array}$ & LIMA et al & 2017 & $\begin{array}{l}\text { Building Information } \\
\text { Modeling (BIM) }\end{array}$ \\
\hline
\end{tabular}

Fonte: Elaboração própria (2019). 


\section{Alternativas inteligentes para a preservação do patrimônio cultural: aplicações para Smart}

Cities

- Técnicas de digitalização 3D

Uma importante proposta no âmbito da preservação patrimonial utilizando tecnologias da informação e da comunicação pode ser observada por meio das técnicas de digitalização em 3D. Moura et al. (2012) propõem a representação tridimensional de acervos museais ou objetos diversos do patrimônio por meio da digitalização 3D para preservar bens culturais em seus mínimos detalhes, de forma segura, permitindo a construção de réplicas para serem utilizadas e estudadas em caso de perdas, ou até mesmo para serem expostas em museus ao invés de seus originais, prevendo a sua conservação.

Até mesmo quando o original já não existe mais, mas os dados quanto as suas dimensões, formato e materiais utilizados ainda estão documentados, é possível de se replicar peças de acervos culturais. É sugerido pelos autores, igualmente, a criação de coleções virtuais acessíveis através da internet para que se detenha um banco de dados preciso quanto ao patrimônio cultural. Isso ajudará na recuperação de informações, podendo contribuir para a disseminação do conhecimento e memória social.

Atualmente, a utilização de conteúdo em 3D é cada vez mais comum em ambientes virtuais de aprendizagem ou sistemas com objetivos pedagógicos, devido ao seu poder de promover a sensação de imersão e sua riqueza de detalhes (ZHU, XIANG E SHENGHONG, 2007). Os autores Moura et al. (2012) sugerem, nesse sentido, que a modelagem tridimensional das peças que compõem um acervo, por exemplo, possam ser representadas e reconstruídas através da ferramenta Blender, que se configura como um software livre e de código aberto para modelagem 3D, e que possui exportador para o padrão X3D, que é aberto para distribuir conteúdo em 3D na Web.

No desenvolvimento da interface gráfica da aplicação, ou seja, na parte visível pelo usuário - que poderá se tratar de um museu virtual, por exemplo, ou de um site específico para carregamento de objetos virtuais relacionados ao patrimônio - os autores utilizaram a linguagem de programação Java em conjunto com o browser Xj3D [Xj3D 2012], para obter uma instância do visualizador e incorporá-lo à interface gráfica.

Gobira e Mozelli (2016) conseguiram, por meio de um projeto da Universidade Estadual de Minas Gerais (UEMG) recriar uma galeria virtual da Escola de Arte Guignard da UEMG, possibilitando a digitalização de diversas obras de arte criando, inclusive, um passeio virtual pelo ciberespaço da instalação. Para isso, os pesquisadores também utilizaram o software de modelagem tridimensional Blender aliado ao ambiente de desenvolvimento Unity para a 
programação da aplicação. Os primeiros testes foram realizados com o Kit de estereoscopia Google CardBoard e também com modelos de aparelhos celulares LG Nexus 5 e Samsumg Galaxy S4 Mini com sistema operacional Android, versões JellyBean e KitKat.

Figura 2: Exemplo de modelagem de peça museal utilizando a ferramenta Blender
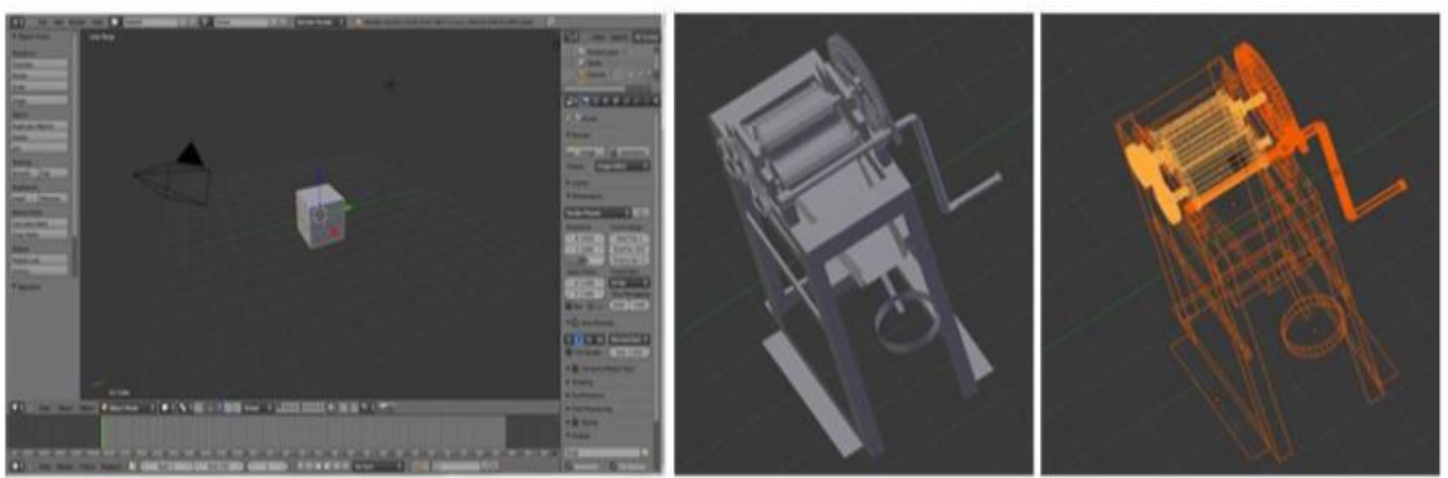

Fonte: Moura et al (2012)

É importante ressaltar, nesse sentido, que, por meio de impressão em 3D é possível reproduzir esses objetos do patrimônio no intuito de utilizá-los em contextos de pesquisas científicas ou até mesmo educativos. Um exemplo que pode elucidar a importância dessa ferramenta são as peças indígenas exclusivas de tribos da América do Sul que foram completamente deterioradas no incêndio do MHN-RJ e que, por serem peças únicas, poderão desaparecer da memória das futuras gerações - que não mais terão condições de conhecê-las devido a sua perda no incêndio em 2018.

Caso essas peças estivessem representadas por meio das ferramentas apresentadas acima, poderíamos, pelo menos, ter a chance de divulgá-las para as próximas gerações como parte do nosso processo cultural evolutivo, salvaguardando o conhecimento e memória social.

- Building Information Modeling (BIM)

O projeto de preservação de um patrimônio cultural demanda um estudo detalhado e criterioso sobre o monumento a ser preservado, envolvendo uma série de etapas com o propósito de prolongar o tempo útil da edificação, integrando conceitos de restauração, manutenção e reabilitação (LIMA et al., 2017).

Radiação solar, partículas do ar, micro-organismos diversos, inundações, fogo, negligências com a conservação preventiva, umidade, roubos e muitos outros são causas de deterioração do patrimônio cultural, que poderão causar - conforme já explicitado acima -perda de arquivos, documentos, peças raras e, inclusive, o desaparecimento de edifícios inteiros caso esses não sejam geridos de forma meticulosa. 
No mesmo contexto em que tratamos do atual paradigma das smart cities, surge uma nova possibilidade de modelagem da informação para edificações que torna possível a extração automática de informações sobre construções. Este modelo, denominado Building Information Modeling (BIM) possibilita consistência, precisão e agilidade de acesso a dados inerentes ao projeto de um monumento de forma organizada e dividida, desde a fase de planejamento e construção até a fase de manutenção e restauro (KEHL, SIVIERO, ISATTO, 2011). Pode-se afirmar, assim, que um dos aspectos mais importantes referentes ao BIM é a possibilidade de gestão da informação de todo o ciclo de vida das edificações, podendo assim, ser utilizado como uma estratégia para a preservação do patrimônio cultural no contexto das smart cities.

Kehl, Siviero e Isatto (2011), por exemplo, utilizaram o BIM como estratégia para preservação de um prédio histórico do século XIX da Universidade Federal do Rio Grande do Sul, denominado "Castelinho". Para isso foi investigada toda a documentação do prédio e os processos gerenciais para a sua manutenção, e, então foi aplicada a modelagem através do BIM por meio do programa computacional Revit da Autodesk.

Conforme observado na Figura 3, com o projeto foi possível organizar as informações relativas aos cômodos do Castelinho, como a data da última vistoria de manutenção, o nome do responsável pela vistoria e a sua aprovação. Informações como essas acrescentadas à tecnologia BIM permitem que profissionais de diferentes áreas que trabalham em um mesmo projeto possam utilizar o mesmo arquivo eletrônico, evitando incompatibilidade ou obsolescência das informações trocadas, tornando mais eficiente as tomadas de decisão quanto à preservação de monumentos históricos.

Figura 3: Planta e cortes gerados a partir de um modelo de BIM aplicado a patrimônio

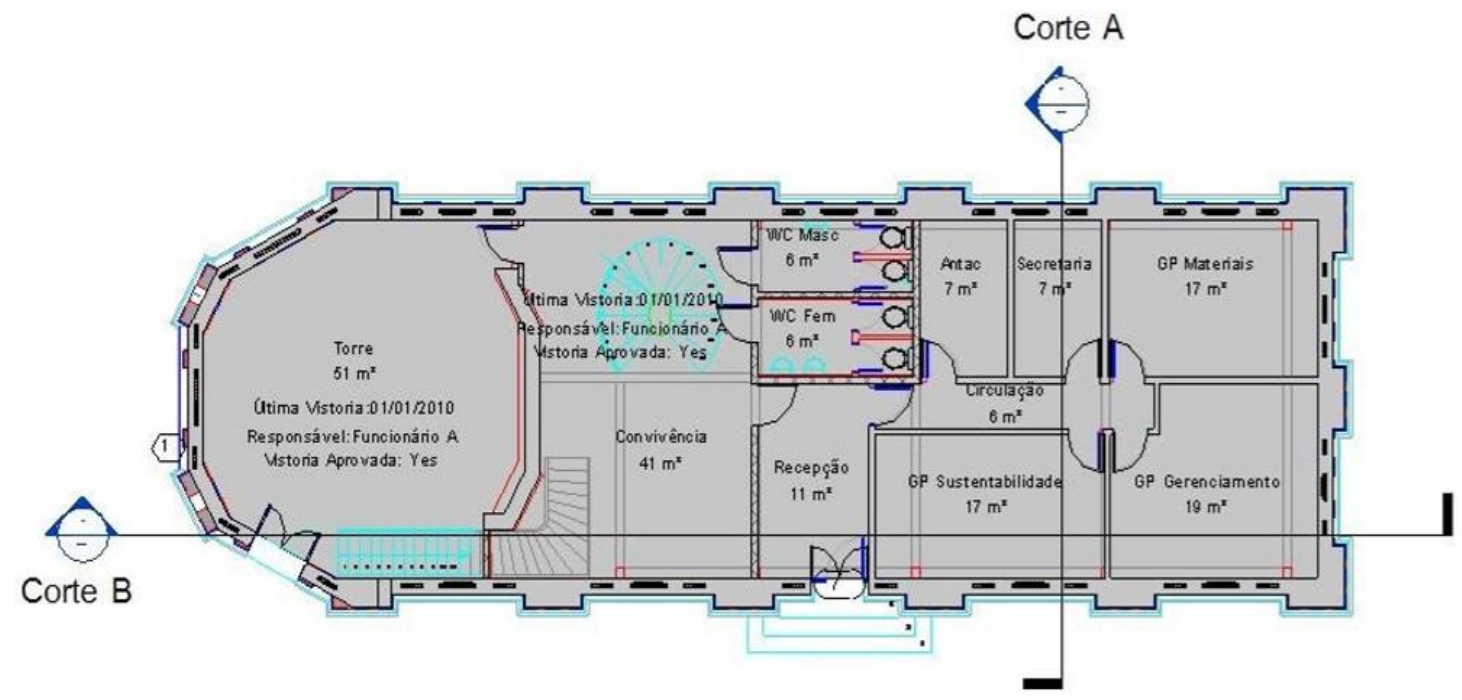

Fonte: KEHL, SIVIERO, ISATTO (2011) 
Ou seja, essas informações organizadas podem fazer com que se aprimore o processo de gestão da conservação de monumentos, já que os responsáveis pela edificação serão capazes de recuperar informações de maneira mais eficiente para diagnosticar o estado de conservação do patrimônio cultural, mapeando patologias para que, enfim, consigam determinar diretrizes de intervenção no edifício, que venham a lidar, por exemplo, com problemas estruturais das instalações, irregularidades elétricas, etc. podendo ser uma chance de minimizar as calamidades observadas na seção anterior.

Lima et al. (2017) discutem um fluxo de trabalho para a produção de mapas de danos de edifícios históricos baseados na metodologia BIM. Segundo os autores, o desenvolvimento de um projeto de intervenção no patrimônio edificado compreende as fases de identificação e conhecimento do bem, resultando em um mapa que determinará os níveis de degradação do patrimônio para auxílio nas tomadas de decisão.

O mapeamento de danos, nesse sentido, é uma das atividades da fase de Diagnóstico do imóvel, que se constitui em um documento gráfico-fotográfico que sintetiza o resultado das investigações sobre alterações estruturais e funcionais nos materiais, nas técnicas, nos sistemas e nos componentes construtivos (LIMA et al., 2017). Além de gerar essas informações gráficas, o mapa de danos também indica o quadro evolutivo do estado de conservação dele, apontando níveis quantitativos qualitativos e de intensidade da degradação atual do edifício.

O interesse dos autores em utilizar a metodologia BIM para a elaboração de um mapa de danos se justifica para a construção de um conjunto de elementos necessários e suficientes para execução das ações destinadas a prolongar o tempo de vida de uma determinada edificação ou conjunto de edificações, englobando os conceitos de restauração, manutenção, estabilização, reabilitação ou outras. Ou seja, por meio da metodologia é possível organizar as informações do edifício patrimonial quanto a suas patologias para que se consiga tomar decisões assertivas para a sua preservação.

Exemplos como esses podem ser utilizados para se começar a refletir sobreas possibilidades de preservação do patrimônio no âmbito das smart cities. Muitos autores inclusive já refletem sobre a ideia de um patrimônio smart, que contemple possibilidades e projetos alternativos conforme os citados. A sorte de se desenvolver projetos nessa conjuntura poderá fazer com que museus, catedrais e monumentos diversos consigam obter longevidade em um contexto urbanístico mutante e, cada vez mais, transformador, acelerado e voraz.

- Aplicativos móveis para gestão participativa da preservação patrimonial

Conforme visto na seção 2 , o crescimento dos dispositivos e aplicativos móveis são praticamente um marco da nossa era. Se em 2016 o número de downloads de aplicativos no 
mundo já ultrapassava a marca de 145 bilhões a previsão é que, para 2021, cheguemos à marca de 350 bilhões (DOGTIEV, 2019). Isso se deve, principalmente, à facilidade com que esses podem ser acessados - por meio de lojas virtuais - além da sua vasta e diferenciada gama de conteúdo ofertada. Assim, desenvolver soluções computacionais no formato de aplicativos móveis representa um meio eficaz de atingir a um público-alvo, cada vez mais, ávido por inovações tecnológicas.

Nesse sentido, Araujo (2017) propõe a criação de um aplicativo móvel destinado ao patrimônio cultural de cidades onde o usuário poderá apontar problemas e classificar os edifícios históricos como "conservado", "pouco conservado" ou "não conservado". A classificação partirá do próprio usuário que poderá, inclusive, justificar o motivo da escolha.0 aplicativo possibilitará também que a pessoa avalie o bem por meio de uma nota quanto ao seu estado de conservação. O conjunto das notas possibilitará identificar quais bens estarão com avaliações inferiores, indicando a necessidade de reparo e/ou manutenção.

Nesse caso, observa-se um esforço de integração das informações entre o cidadão e a própria gestão do patrimônio em questão, que recebe um feedback do visitante via aplicativo, podendo utilizar esse retorno nas suas tomadas de decisão, por exemplo. Araujo (2017) salienta que o protótipo poderá auxiliar no processo de conscientização do cidadão quanto à importância da preservação do patrimônio cultural, uma vez que fornecerá as fontes informacionais necessárias para que o usuário passe por um processo íntimo e mental de compreensão da importância da salvaguarda. Assim, visto que o cidadão tenha sido despertado a importância da preservação poderá se tornar vigilante, fiscal e interessado no assunto, colaborando, inclusive, com o desenvolvimento de uma cidade participativa e, cada vez mais, inteligente.

- Utilização de sensores conectados ao acervo patrimonial para coleta e análise de dados em tempo real

A utilização de sensores, conforme vimos anteriormente, é uma prática que vem sendo amplamente utilizada devido a sua variedade de uso, que permite a coleta de dados tanto de objetos, quanto de ambientes como um todo.

Guths (2004) esclarece que uma das primeiras providências na política de preservação do patrimônio é o conhecimento e acompanhamento da temperatura do ambiente no qual o acervo está salvaguardado. $\mathrm{O}$ autor, nesse sentido, desenvolveu, por meio de uma pesquisa do Departamento de Engenharia Mecânica da Universidade Federal de Santa Catarina um sistema de aquisição e tratamento de sinais específicos para a área de preservação de acervos, denominado sistema CLIMUS. 
A tecnologia foi desenvolvida por meio de sensores que captam a temperatura do ambiente, que por sua vez, comunicam-se com um microcomputador.Nesse sentido introduzse o conceito de Internet das coisas, onde o armazenamento de dados é realizado em servidores alojados na Internet a partir de sensores ou chips instalados em objetos variados. A partir dos dados obtidos é determinado em tempo real o Índice de Preservação do acervo que é um parâmetro que fornece uma previsão do tempo de degradação por ação química de um material orgânico frágil. Os dados obtidos são registrados automaticamente no disco rígido do microcomputador e igualmente apresentado na tela sob a planta baixa da edificação. A visualização e o tratamento dos dados são facilitados por um software específico (ClimusVisual), bastando selecionar as salas e o período do ano que se deseja analisar e, então, os gráficos são automaticamente montados, podendo então ser exportados para outros programas ou ser impressos (GUTHS, 2004).

É importante ressaltar que o sistema permite a expansão do número de sensores e a incorporação de sensores de luminosidade, radiação ultravioleta, condensação em parede, qualidade do ar, além de detectores de incêndio, podendo, assim, se transformar em um dispositivo de segurança adicional.

Segurado (2017) propõe um sistema integrado de multi-sensores para a aplicação em edifícios históricos visando a sua preservação. $O$ autor desenvolveu e testou um sistema inovador de gestão, computação na nuvem (em inglês, o conhecido termo de "Cloud Computing") e a Internet das coisas, que permitiram realizar um acompanhamento e uma análise do sistema em tempo real.

O projeto consistiu em criar um sistema de sensores inteligentes comunicando entre si para gerir eficazmente o patrimônio da qual ele está inserido. Este conjunto de sensores transmite os dados de forma wireless e processa a informação através de algoritmos desenvolvidos. Desta maneira se controla a iluminação e a passagem de pessoas ou as fendas de edificação com acelerómetros e fissurômetros. Do mesmo modo, detecta-se organismos xilófagos como térmitas ou caruncho e consegue-se recolher os níveis de dióxido de carbono, temperatura e umidade, no sentido de evitar fungos de putrefação na madeira que poderiam estragar rapidamente retábulos, artesanato e outras peças de valor incomensurável. Para isso, o autor utiliza sensores de movimento, temperatura, umidade, luminosidade e um dispositivo bluetooth.

Sendo assim, a conjugação da monitorização dos edifícios históricos através do recolhimento de dados de temperatura, umidade e luminosidade, bem como a utilização de sensores de movimento, permite aumentar significativamente a sustentabilidade do patrimônio cultural, face às gerações futuras, posto que se consegue, por meio de análise dos 
dados provenientes dos sensores, uma conservação preventiva do edifício e do seu acervo, assim como, a possibilidade de tomadas de decisões emergenciais face a um desastre repentino.

\section{Considerações finais}

A preservação do patrimônio cultural, do conhecimento e da memória social são imperativos para o desenvolvimento da cultura e do próprio ser humano. Alternativas que visem agregar o uso das tecnologias da informação e da comunicação como auxílio na conservação delegados materiais e imateriais em um contexto urbano, ampliam as possibilidades de salvaguarda e auxiliam gestores nas melhores tomadas de decisões em vista da preservação patrimonial.

Os objetivos delineados no início desta investigação foram atingidos de maneira satisfatória, dentro dos limites impostos pelos recursos e tempos disponíveis. De todo modo, é de suma importância ressaltar que, caso não haja interesse do Estado no investimento e manutenção de políticas para aplicação das tecnologias mencionadas, no patrimônio cultural, ou, caso os gestores desses patrimônios não comecem a refletir quanto a alternativas inteligentes e criativas, de menor custo de instalação e manutenção, por exemplo, nada mudará. Continuaremos a perder o nosso frágil e rico patrimônio para o tempo, para o fogo, e para as intempéries resultantes da célere urbanização que vivemos.

Durante a avaliação das investigações estudadas, percebeu-se a existência de uma gama de outras alternativas que podem também ser pensadas no contexto analisado por nós, como a fotogrametria digital utilizada na construção de modelos matemáticos para obter uma representação das edificações históricas na forma de relevos, visadas ortogonais e modelos tridimensionais, descrevendo as anomalias do edifício, de forma que os locais mais prejudicados por patologias diversas sejam apontados para que se possa iniciar um processo de reconstrução/restauração.

É sabido que ainda existem muitas lacunas a serem sanadas na intenção de se utilizar as TIC no processo de preservação patrimonial das cidades, desde a escassa literatura que se dedica a relacionar essas tecnologias na preservação do patrimônio até as divergências e pressões políticas e sociais que enfrentam os gestores desses espaços. Muito ainda precisa ser feito, discutido e repensado. Mas também é sabido que precisamos começar de alguma forma, uma vez que a pauta sobre a preservação do patrimônio é urgente.

\section{Referências}


ARAUJO, A. K. P. T. A gestão da informação na proteção do patrimônio cultural material. Dissertação de Mestrado do Programa de Pós-Graduação em Gestão \& Organização do Conhecimento (PPG-GOC). Universidade Federal de Minas Gerais, Belo Horizonte, 2017. 87 p.

BARACHO, R. M. A.; SOERGEL, D. ; PEREIRA JUNIOR, M. L. ; HENRIQUES, M. A. A Proposal for Developing a Comprehensive Ontology for Smart Cities/ Smart Buildings / Smart Life. In: INTERNATIONAL MULTI-CONFERENCE ON COMPLEXITY, INFORMATICS AND CYBERNETICS, $10^{\text {th }}$, 2019, Orlando. IMCIC 2019. Proceedings. Orlando, FL: IIIS, 2019. v. 2, p. 110-115.

BELO HORIZONTE. Prefeitura Municipal. Dados abertos. Disponível em: $<$ https://prefeitura.pbh.gov.br/bhtrans/informacoes/dados/dados-abertos> Acesso: 13/07/2019.

BENTO, A. Como fazer uma revisão da literatura: Considerações teóricas e práticas. Revista JA (Associação Académica da Universidade da Madeira),v. 7, p. 42-44, 2012. ISSN: 1647-8975.

BOGÉA, K. Tragédia do Museu Nacional - Entrevista em vídeo para o Jornal Nacional, Globo (completo). Set. 2018. Disponível em: <https://www.youtube.com/watch?v=L3-Od3wZXIk> Acesso: 20/08/2019.

DOGTIEV, A. App Download and Usage Statistics (2018). Revista Business of Apps. Disponível em: <http://www.businessofapps.com/data/app-statistics/\#1> Acesso em: 01/06/2019.

FIGUEIREDO, G. M. P. O discurso e a prática da Smart City: perspectivas críticas e aproximações sistemáticas no contexto de metrópoles latino-americanas. Dissertação de mestrado do Programa de Arquitetura e Urbanismo da Universidade de São Paulo. São Paulo, $2018,142 \mathrm{p}$.

FUNARI, P. P. A. Os desafios da destruição e conservação do Patrimônio Cultural no Brasil. Trabalhos de Antropologia e Etnologia, Porto, v. 41, p. 23-32, 2001.

GOBIRA, P.; MOZELLI, A. As interfaces de realidade virtual no século XXI. Z Cultural - Revista do Programa Avançado de Cultura Contemporânea, Rio de Janeiro, v. 2, p. 1-15, 2016.

GUTHS, S. Monitoramento e controle térmico para preservação de acervos. Revista do Arquivo Público Municipal de Indaiatuba, v. 3, n. 3, p. 61-70, 2004.

INNARELLI, H. C. Preservação Digital: a influência da gestão dos documentos digitais na preservação da informação e da cultura. Revista Digital de Biblioteconomia e Ciência da Informação, Campinas, v. 8, n. 2, p. 72-87, jan./jun. 2011.

KEHL, C.; SIVIERO, L. A.; ISATTO, E. L. A tecnologia BIM na documentação e gestão da manutenção de edifícios históricos. In: ENCONTRO DE TECNOLOGIA DE INFORMAÇÃO E COMUNICAÇÃO NA CONSTRUÇÃO CIVIL, 5., TIC 2011, Salvador. V TIC. Salvador, 2011.

KELLNER, A. W. A. A reconstrução do Museu Nacional: bom para o Rio, bom para o Brasil! Ciência e Cultura, São Paulo, v. 71, n. 3, 2019. Disponível em: <http://cienciaecultura.bvs.br/pdf/cic/v71n3/v71n3a02.pdf > Acesso em: 19/08/2019.

LIMA, Rogério H. F.; ARAÚJO, Bruno Gonçalves; PAZ, Gracy; OLIVEIRA, Isi Monelline. Mapa de danos de edificações históricas utilizando a metodologia BIM. In: SIMPÓSIO BRASILEIRO DE 
TECNOLOGIA DA INFORMAÇÃO E COMUNICAÇÃO NA CONSTRUÇÃO, 1.; SIMPÓSIO BRASILEIRO DE GESTÃO E ECONOMIA DA CONSTRUÇÃO, 10. Elaboração. Fortaleza, Ceará. 2017.

MUSEU HISTÓRICO NACIONAL (MHN). Acervo (Arquivístico, Bibliográfico, Museológico e Publicações). Disponível em: <http://mhn.museus.gov.br/index.php/acervo/> Acesso: 04/06/2019.

MOURA, I. B. G.; LIMA, J. D.; NETO, F. M. M.; MAIA, P. S. S. MUSERT: Um museu virtual em 3D para a preservação do Patrimônio Histórico e Cultural. In: JORNADA DE INFORMÁTICA DO MARANHÃO,4.,2012. Anais. São Luiz: Universidade Federal do Maranhão, 2012.

ORGANIZAÇÃO NAS NAÇÕES UNIDAS (ONU).Department of Economic and Social Affairs, Population Division. World urbanization prospects: The 2015 revision, key findings \& advance tables. New York, United Nations, 2015.

RIGANTI, P. Smart cities and heritage conservation: developing a smartheritage agenda for sustainable inclusive communities. International Journal of Architectural Research - ArchnetIJAR, v. 11, n. 3, p. 16-27, November 2017. Regular Section.

ROZESTRATEN, A. S. Dúvidas, fantasias e delírio: smart cities, uma aproximação crítica. In: COLÓQUIO INTERNACIONAL ICHT 2016, 1., Imaginário: Construir e Habitar a Terra, 16 a 17 de março, 2016, São Paulo. Atas do Io Colóquio Internacional ICHT. São Paulo: FAU/USP, p. 15-30, 2016.

SEGURADO, D. L. V. Sistema de Cloud baseado em dispositivo multi-sensor para aplicação em edifícios históricos. Dissertação para Obtenção do Grau de Mestre em Engenharia Eletrotécnica e de Computadores. Universidade Nova de Lisboa, Portugal, 2017. 91 p.

SILVA, E. P. S. Património e identidade: os desafios do turismo cultural. Revista Antropológicas, v. 4; n. 4, p. 217-224, 2000.

UNIVERSIDADE DE SÃO PAULO. Instituto de Estudos Avançados. Memória cultural: o vínculo entre passado, presente e futuro. Publicado em: 23/05/2013. Disponível em: $<$ http://www.iea.usp.br/noticias/memoria-cultural>. Acesso: 20/05/2019.

VANNUCCI, P.; MASI, F.; STEFANOU, I.; MAFFI-BERTHIER, V. Structural integrity of Notre Dame Cathedral after the fire of April 15th, 2019. HAL archives-ouverts, 2019. Disponivel em: <https://hal.archives-ouvertes.fr/hal-02105786v2/document > Acesso em: 28/08/2019.

ZHU, Q., XIANG, K., SHENGHONG, H. Design an Immersive Interactive Museum in Second Life. In: WORKSHOP ON DIGITAL MEDIA ITS APPLICATIONS IN MUSEUM \& HERITAGES, 2., 2007. p. 264-267, December 2007. 